\title{
Hologramas semânticos: uma proposta metateórica para a avaliação do significado complexo na linguagem natural
}

\section{Semantic holograms: a metatheoretical proposal toward the evaluation of complex meaning within natural language}

Doutorando em Letras com concentração em Linguística, Programa de Pós-Graduação em Letras, PUCRS. Este artigo se pauta pelo Projeto de Pesquisa do CNPq, "Modalidade Lógica: um estudo de interfaces", e pelo Grupo de Pesquisa do CNPq, Logica e Linguagem Natural. Sendo um recorte da dissertação de mestrado do autor, com apoin da Coordenação de Aperfecomento de Pessoal Nivel Superior (CAPES) - Código de Financiamento 001. (3) http://orcid.org/0000-0002-3509-822 E-mail: penz.linguistics@gmail.com

Recebido em: 19/12/2018. Aprovado em: 28/2/2019,

Endereço para correspondência: Programa de Pós-Graduação em Letras Av. Ipiranga, 6681 - Partenon 90619-900, Porto Alegre, RS, Brasil
Yuri Fernando da Silva Penz ${ }^{1}$

\section{RESUMO}

Este trabalho se propõe a avaliar as dimensões da causalidade enquanto fenômeno aquém e além da instância semântica, identificável por meio da aproximação entre significado da sentença e do falante, expressa neste trabalho a partir da relação causa/efeito viabilizada pela modalidade. Assume-se que o fenômeno causal, representando tanto sua pertinência para a cognição humana quanto âmbitos mais amplos da gramática, inserese na categoria de significado complexo, requerendo auxílio das disciplinas de sintaxe e pragmática para o estudo semiformal de sua natureza e ocorrência no âmbito lógico-linguístico. Posto isso, o artigo está organizado a partir da seguinte estrutura: a) o fenômeno causal e a sua expressão em linguagem natural via modalidade com suas respectivas implicações para i) a comunicação cotidiana; ii) a linguagem científica; e iii) a ontologia das Filosofias da Mente, da Lógica, da Linguagem, da Linguística e da Ciência; b) a constituição da holografia semântica a partir de uma proposta metateórica assentada na interface lógica vs. linguagem natural; e c) a análise do significado complexo a partir do fenômeno causal via modalidade na interface i) sintaxe/semântica e ii) semântica/pragmática enquanto hologramas simétricos.

Palavras-chave: Modalidade. Holografia semântica. Metateoria das Interfaces. Lógica e linguagem natural.

\section{ABSTRACT}

This paper proposes to evaluate the dimensions of causality as a phenomenon below and beyond the semantic instance, identifiable by means of the approximation between sentence meaning and speaker meaning, which is expressed through the relation between cause/effect feasible by modality. It is assumed that the causal phenomenon, representing both its relevance to human cognition and wider scopes of grammar, falls within the category of complex meaning, requiring the aid of the syntactic and pragmatic disciplines for the semiformal study of its nature and occurrence in the logical-linguistic sphere. Thus, this article is organized according to the following structure: a) the causal phenomenon and its expression within natural language via modality regarding its respective implications for i) everyday communication, ii) scientific language and iii) the ontology of Mind's, Logic's, Language's, Linguistics' and Science's Philosophy; b) the constitution of semantic holography by means of a metatheoretical proposal sustained by an interface between logic and natural language; and c) the analysis of complex meaning of causality via modality on the interface between i) syntax and semantics and ii) semantics and pragmatics as symmetrical holograms.

Keywords: Modality. Semantic holography. Metatheory of Interfaces. Logic and natural language. 


\section{Introdução}

A natureza da proximidade entre Linguística e Filosofia tem sido tópico de discussão para alguns dos problemas epistemológicos mais ásperos do último século no que diz respeito à linguagem: o que é a linguagem humana? Essa pergunta aparentemente trivial tem incitado uma série de questões em torno da natureza dos fundamentos de ambas as áreas (e também de muitas outras) e das devidas implicações que se produzem a partir de como se caracterizam cada uma dessas disciplinas. A principal responsabilidade sobre essa aproximação jaz, provavelmente, no seio da Semântica, possível subdisciplina de ambas áreas. Ao passo que o comprometimento da Semântica na agenda de um linguista se presta à descrição dos sistemas de significado independente de contexto das línguas naturais, a Semântica no roteiro de formação de um filósofo tende a expressar-se como elemento fundamental para a Ontologia, a Metafísica e a Modalidade, por exemplo. Contudo, a questão sobre do que se trata o significado é justamente o que relativiza os fundamentos linguísticos e filosóficos, tendo implicações relevantes para a primeira pergunta, sobre o que, afinal, é a linguagem humana.

\section{A causalidade na semântica e a semântica na filosofia}

Grice $(1957 ; 1967)$ dedicou a maior extensão de seus trabalhos ao tratamento do significado em linguagem natural a partir da relação entre entidades linguísticas e operadores lógicos, localizando tal paradigma em uma esfera de racionalidade ampla. Similarmente, Bach $(1986 ; 1989)$ desenvolve a sua abordagem em Semântica Formal a partir de fundamentos relevantes que se tornam salientes para a compreensão per se de o que é a linguagem e o que é a Linguística observadas a partir de tal ótica. Já no campo mais árido do tratamento do dado linguístico, por meio dos universais e da tipologia linguística (COMRIE, 1981) torna-se possível estipular parâmetros (CHIERCHIA, 1988) semânticos da mesma maneira como são propostos aqueles de natureza fonológica ou sintática.

Expondo o amplo e complexo caráter da agenda semântica, Bach (1989) direciona parte de sua discussão em torno dos universais e de aspectos semânticos no tocante à relação mente/mundo, conduzindo a um debate clássico sobre o significado:

a) Significados são determinados pelo pensamento, organizando-se em categorias cognitivas que são compartilhadas pela espécie humana.

b) Significados se determinam a partir de como se estrutura o mundo, o qual é habitado e compartilhado pela espécie humana.

A obra de Bach se pauta por uma abordagem logicista, operando caracteristicamente no paradigma formalista para uma semântica das línguas naturais, seguindo como referência o trabalho de Montague (1974). O autor, contudo, admite que mais do que uma Gramática Universal, assunção teórica em comum entre os fundamentos formalistas de Montague (1974) e as bases cognitivo-formais de Chomsky (1995), é preciso assumir uma Faculdade da Linguagem para lidar com a interpretação dos sistemas de cálculo da linguagem humana.

Abordagens similares, como as oferecidas em Hornstein (1984), Heim e Kratzer (1998), Ludlow (1999) e Chierchia e McConnel-Ginet (2000), têm sido cada vez mais dirigidas para uma acomodação entre os aspectos formais que competem à constituição de uma gramática e as bases cognitivas indispensáveis para localizar tal gramática como um módulo especializado ou integrado na configuração cérebro-mente. Sem favor algum, Kratzer $(1981 ; 1991 ; 2005 ; 2013 ; 2016)$ é uma das personalidades teóricas que mais tem investido fôlego na instituição da Semântica Formal sob a égide de uma abordagem naturalista, admitindo-se assim uma Faculdade da Linguagem em sentido amplo e restrito em direção ao tratamento do significado. 0 
trabalho de Kratzer, sobretudo, tem versado acerca da modalidade das línguas naturais como estrutura gramatical e semântica que intersecciona elementos cognitivos e computacionais em igualdade. Dada uma sentença como (1):

(1) Se a chaleira está apitando, a água deve ter fervido

Seria possível abordar, na esteira dos trabalhos sobre modalidade, uma série de aspectos relevantes como: a) condicionais; b) verbos auxiliares; e c) evidencialidade. Há, contudo, ainda dois elementos pouco salientes a se discutir, os quais este trabalho pretende justamente abordar: d) causalidade e e) racionalidade ampla.

São respectivamente Hume e Kant (DE PIERRIS; FRIEDMAN, 2018) as referências teóricas clássicas mais substanciais sobre o fenômeno causal na literatura da Filosofia, nenhum dos quais demonstra preocupações diretas sobre o que tem ou não a linguagem a ver com a relação causa vs. efeito. Ambos, por outro lado, estabelecem uma interação tácita entre essa relação e i) as disposições cognitivas do ser humano para reconhecê-la e manipulála a priori e ii) as disposições formais que constituem a estrutura lógica do mundo, de modo a admitir que um evento "a" seja causador de outro evento "b", de maneira necessária.

Posto assim, convém, nesta seção, localizar o fenômeno causal e a sua expressão em linguagem natural via modalidade com as suas respectivas implicações para a) a comunicação cotidiana; b) a linguagem científica; e c) a ontologia das Filosofias da Mente, da Lógica, da Linguagem, da Linguística e da Ciência.

\subsection{Causalidade e comunicação cotidiana}

A preocupação com a manifestação da noção de causalidade na linguagem cotidiana caracteriza, precisamente, a legitimação do embate entre o empirismo e o conhecimento a priori, assim como na relação das implicações comunicativas que se detêm a partir da interação entre os aspectos cognitivos e computacionais de uma base modal ${ }^{1}$. Aristóteles já anunciara um aspecto relevante acerca da causalidade na esfera entre conhecimento e crença, conforme apontam Morris e Brown ([2014], tradução nossa) ${ }^{2}$ :

Aristóteles (384-322 DC) esboçou uma distinção absolutamente categórica entre conhecimento científico e crença. Conhecimento científico consistia do conhecimento de causas e a explanação científica repousava na demonstração - provar a conexão necessária entre uma causa e o seu efeito a partir de premissas intuitivamente óbvias independentemente da experiência.

Grosseiramente, é admissível afirmar que, enquanto na subseção atual se trata da crença, na subseção seguinte é abordado o conhecimento científico via questões de fato, ambos subordinados à noção lato sensu da causalidade. A categoria de modalidade é entendida como fundamental na mediação entre tais instâncias no sentido de que veicula apropriadamente a noção de mundos possíveis, autorizando um agente a falar sobre o que é provável, possível, necessário ou obrigatório. Assim, uma sentença como (1) passa a receber uma leitura epistêmica no sentido de que projeta mundos possíveis os quais são compatíveis com a crença de que "é provável" que a água esteja fervendo "porque" chaleiras chiam quando o seu conteúdo líquido atinge o ponto de ebulição, de modo que a proposição expressa por (1) seja verdadeira em tais mundos.

${ }^{1}$ A razão, sobretudo, para esta preocupação está assentada em pelo menos três instâncias, sendo a) a interação entre conhecimento ordinário e científico mediado pela causalidade; b) na instituicão de uma racionalidade ampla entre operadores logicos e linguísticos; ec) na constituição holográfica entre sintaxe/semântica e semântica/pragmática.

2 Do original: Aristotle (384-322 BCE) drew an absolute categorical distinction between scientific knowledge (scientia) and belief (opinio). Scientific knowledge was knowledge of causes and scientificic knowledge (scientia) (384 belief (opinio). Scientific knowledge was knowistedge of causes and scientific from intuitively obvious premises independently of experience. 
A despeito, portanto, das propriedades sobre condicionais, verbos auxiliares e evidencialidade, o foco atualmente repousa sobre a noção causal e a racionalidade ampla veiculadas a partir da modalidade ${ }^{3}$ Busca-se, majoritariamente, ilustrar como a causalidade se expressa na comunicação cotidiana, além de como a modalidade auxilia nesse empreendimento. Tome-se (2) como mais um caso:

(2) A: É provável que chova, pois o céu esteve escuro durante o dia inteiro B: Ontem passou dia assim, e não caiu uma gota!

Segundo o qual (2a) expressa a modalidade epistêmica a partir da estrutura sentencial "é provável". Nesse cenário, similarmente ao que se observa em (1), (2a) trata dos mundos com os quais a crença do falante é compatível, mundos em que uma proposição $\varphi$ implique outra proposição ४, como (3):

(3) Se o céu está escuro $(\varphi)$, então chove $(\psi)$

(4) Se P, então Q

(5) $\mathrm{P} \rightarrow \mathrm{Q}$.

O presente cálculo inferencial, por sua vez, apresenta caráter não monotônico, já que, nos fundamentos de uma lógica clássica aristotélica, sequer existe operador para a noção de causalidade. Em termos estritos, uma sentença como (6) ilustra por quê:

(6) Como $\left[{ }_{t}\right]$ não coloca despertador, João $o_{t}$ se atrasa todos os dias

\footnotetext{
${ }^{3}$ Embora haja o emprego de verbos auxiliares modais para ilustrar a noção de modalidade em certos exemplos, outras formas linguísticas, como adjetivos ou advérbios, podem satisfazer a interpretação modal, às quais se recorre durante a discussão do fenômeno. Os demais elementos também serão colateralmente abordados, mas, reitera-se, não constituem foco para esta análise.
}

de acordo com a qual tanto as proposições (7) quanto (8) podem ser verdadeiras sem que uma seja o efeito da outra:

(7) João não coloca despertador

(8) João se atrasa todos os dias.

Dessa forma, o valor-verdade atribuído a (6) não necessariamente se dá a partir da conjunção causal entre $\alpha$ e $\beta$, sendo a implicação não necessária, apenas contingente. Esse problema não é diretamente evitado por uma abordagem em Lógica Modal, mas esta oferece recursos de que a Lógica Clássica não dispõe; notadamente, a partir da modalização, existe um conjunto de mundos que é compatível com a declaração em (6) ao passo que existe também um conjunto de mundos que não o é. 0 caso do comunicador (2a), por exemplo, ilustra um conjunto de mundos que é incompatível com as crenças do receptor $(2 \mathrm{~b})$.

Contudo, a noção de causa se expressa pelas mais distintas formas na comunicação cotidiana, frequentemente dispensando o recurso da modalidade e, assim como em (6), ignorando aspectos mais espessos da causalidade a rigor, como uma arquitetura de eventos ou atribuição de falácias. As questões que permanecem são: por que existe a modalidade na expressão desse tipo de fenômeno e qual é a diferença que essa categoria proporciona?

\subsection{Causalidade e linguagem científica}

Assume-se " $x$ " de modo que " $x$ " equivale a "a Semântica é a linguagem da Ciência". Nesse caso, "x" trata-se de uma declaração que é tanto problemática quanto também é ilustrativa:

(9) A Semântica é a linguagem da Ciência 
(10) Necessariamente, a Semântica é a linguagem da Ciência

(11) Possivelmente, a Semântica é a linguagem da Ciência.

O contraste estabelecido entre (9)-(11) não está meramente ancorado na forma fonológica, tendo o seu relevo evidente sobretudo a partir da Forma Lógica:

$$
\begin{array}{ll}
\text { (9a) } & \exists x\left(S(x)^{\wedge} \forall y(S(y) \rightarrow x=y)^{\wedge} \mathrm{LC}(x)\right) \\
(10 a) & \square \exists x\left(S(x)^{\wedge} \forall y(S(y) \rightarrow x=y)^{\wedge} \mathrm{LC}(x)\right) \\
\text { (11a) } & \diamond \exists x\left(S(x)^{\wedge} \forall y(S(y) \rightarrow x=y)^{\wedge} \mathrm{LC}(x)\right) .
\end{array}
$$

Embora os falantes nativos do português sejam hábeis em identificar a distinção, não parece crível que igualmente saibam descrevê-la ou explicá-la. A modalidade é, pois, uma das evidências da relevância da Semântica enquanto componente gramatical de uma interface conceptual/intensional, haja vista que sintaticamente (10) e (11) são equivalentes, distinguindo-se em relação àquilo que significa ser necessário que em todos os mundos possíveis a Semântica seja a linguagem da Ciência (10a) e ser possível que em pelo menos um dos mundos possíveis a Semântica seja a linguagem da Ciência (11a).

Classicamente, a Semântica Formal tem-se preocupado com a atribuição do valor-verdade à proposição que informe um determinado estado de coisas sobre o mundo atual ou sobre mundos possíveis, permitindo não apenas falar sobre o verdadeiro e o falso de acordo com a intuição que um falante tem sobre como se estrutura a realidade à sua percepção, como também sobre em que condições uma proposição poderia ser verdadeira, mesmo que não o seja na atualidade. Aliás, pela própria condição de dada proposição tomada na atualidade, somada à sua composicional intensional, é possível estipular quais mundos são mais próximos ou distantes do atual em termos extensionais.
No que concerne à causalidade, portanto, esse tipo de abordagem se mostra relevante diante dos contrafactuais, dos condicionais, da possibilidade de se referir ao real e ao irreal etc., tendo-se em vista que a causa parece ser por excelência a condução de um estado de coisas para outro. É de fato Lewis (1973), a referência moderna mais relevante para a discussão do fenômeno causal, reinterpretando algo da contribuição de Hume a partir de uma abordagem lógica da contrafactualidade. A escola filosófica a que Lewis se filia, contudo, posiciona-se de maneira contrária à linha de abordagem dominante acerca da modalidade contemporaneamente, a qual foi inaugurada por Kripke (1980). O debate se situa respectivamente entre concretistas e atualistas, cuja distinção primordial se situa na caracterização ontológica de mundos possíveis.

Independentemente das implicações metafísicas que se obtêm a partir de ambas as decisões metodológicas, a noção modal parece ser um fenômeno ainda mais substancial para a cognição humana, como se, apesar da teorização, permanecesse a intuição de que o mundo poderia ter sido de alguma maneira diferente em pelo menos um de seus estados. Jaz nesse ínterim a distinção mais significativa entre uma abordagem lógica de predicados de primeira ordem e qualquer abordagem modal, quer concretista, quer atualista, estando igualmente nesse âmbito a principal razão para reconhecer a Semântica como a disciplina linguística mais genuinamente preocupada com a linguagem científica.

Desde Peirce (1931-1958), Morris (1938) e Carnap (1938), a Semântica tem sido caracterizada como a relação estabelecida entre o signo linguístico, qualquer que seja essa identidade, e o mundo. Apesar de uma série de problemas topicalizados, uma longa geração de semanticistas formais, desde o Programa Logicista, tem investido fôlego teórico na noção de significado independente de contexto a partir da correspondência entre sentido e referência, aprimorando constantemente os modelos operacionais 
a partir dos quais se propõem as análises das sentenças das línguas naturais. O compromisso ontológico via aboutness, contudo, permanece em vigor, aprimorado sob a ótica da modalidade.

A caracterização do comprometimento sério estabelecido entre a Semântica e a cientificidade já está assentada no próprio fator de metalinguagem que a abordagem formal do significado linguístico assume como necessário para o firmamento do seu estatuto como subdisciplina linguística ${ }^{4}$. Na esteira da relação formalismo vs. modalidade, a noção causal parece refletir-se como uma espécie de designador-rígido, comprometendose com leis físicas e lógicas ao longo do conjunto de mundos possíveis representados a partir de uma proposição. Naturalmente, essa relação é sensível ao fundamento teórico do qual se parte, já que uma base concretista é mais sensível às implicações físicas deônticas que regeriam os demais mundos, a exemplo do atual, ao passo que atualistas postulam uma relação estritamente lógico-linguística, segundo a qual o mundo possível (ou o conjunto de mundos possíveis) é acessível exclusivamente via proposição.

É via mundos possíveis, ainda assim, que se torna possível discutir as bases do que é causal e do que é contingente, por meio do que se pode denotar como necessário, como possível, como obrigatório de acordo com um conjunto de regras ou provável segundo a crença de um conjunto de agentes de certo mundo. Apesar das metodologias específicas de cada área do saber, as proposições são as entidades que validam logicamente, confirmam como verdadeiras ou falsas as relações premissa/conclusão ou, ainda, permitem acesso ao conteúdo informativo de um dado estado de coisas. A relevância da Semântica nessa perspectiva proporciona duas hipóteses: ou i) a semântica da linguagem natural não distingue conhecimento ordinário de científico (nem qualquer tipo de conhecimento), servindo

${ }^{4}$ Esse aspecto será mais bem discutido na seção segunda deste trabalho. apenas de mediadora entre propriedades intensionais e extensionais ou ii) cada área do conhecimento dispõe de sua própria semântica, admitindo-a como subdisciplina da Filosofia, da Lógica, da Linguística, da Semiótica, da Matemática, da Computação etc. Seja como for, não parece plausível apresentar-se a ontologia de qualquer ciência sem essa entidade, a qual medeia o que quer que seja entre sentido e referência para significar.

\subsection{As ontologias semânticas}

Notadamente, Peirce, Carnap e Morris parecem estipular diferentes tipos de sintaxe, semântica e pragmática de acordo com as distintas necessidades entre as áreas do conhecimento diversas que exigem essa espécie de entidade. Dado que, segundo uma respeitável tradição, a Semiótica ${ }^{5}$ é a área da qual a Linguística herda seu caráter ontológico, referindo-se ao signo linguístico, essa própria linha de raciocínio conduz ao pressuposto de que signos são entidades formais e abstratas que podem espraiar-se para distintas áreas do conhecimento, sendo caracterizadas e autenticadas no seio de cada disciplina.

A causalidade, por sua vez, também figura como entidade formal, cuja fenomenologia pode estender-se a uma ampla gama de disciplinas, teorias, linhas investigativas etc. Em uma extensa obra sobre a causalidade enquanto entidade fenomenológica, Pearl (2000) tece uma longa exposição sobre a adequação descritivo-explanatória que se faz necessária em virtude de legitimar inferências causa-efeito em um cenário empirista. Em um de seus recortes, o autor se dedica a versar sobre a representação formal da informação causal em contextos de implicação, propondo-se, no quadro empirista, a analisar cálculos inferenciais passíveis de ser continentes de valor causal imanente, cuja derivação, a partir de tal cadeia informativa,

5 Ou Semiologia, nesse mesmo cenário, caso seja assumida uma linhagem europeia. 
possa corresponder formalmente, a corolários e acarretamentos na relação causa vs. efeito.

A preocupação de Pearl, portanto, vem ao encontro da relação entre a causalidade e a instância da linguagem científica (2000, p. 45-46, tradução nossa $)^{6}$ :

Diz-se de uma variável $X$ que tem uma influência causal sobre uma variável $\mathrm{Y}$ se um trajeto direto de $\mathrm{X}$ até $\mathrm{Y}$ existe em cada minima estrutura consistente com os dados. [...] Posto P, uma variável C apresenta uma influência causal na variável E se e somente se existe um trajeto direto de $\mathrm{C}$ até $\mathrm{E}$ em cada minima estrutura latent consistente com $\mathrm{P}$.

o que não deixa o quadro em condições nem mais nem menos satisfatórias, tendo-se em vista que a relação problemática, já apontada por Hume, e operacionalizada por Lewis, persiste: como determinar que um evento $C$ cause outro evento $E$ de maneira genuína, para além da percepção cognitiva humana? Nas palavras de Lewis (1973, p. 556, tradução nossa) ${ }^{7}$ :

Nós subordinamos causas e efeitos em regularidades por meio das descrições que essas entidades satisfazem, não por semelhança geral. E autorizamos uma causa a ser apenas uma parte indispensável, e não o todo, que se segue a partir do efeito em acordo com a lei. Em analyses de regularidade da aualidade, uma causa é definida grosseiramente como qualquer membro de qualquer mínimo conjunto de condições genuínas que são conjuntamente suficientes, dadas as leis, para a existência do efeito.

${ }^{6}$ Do original: $A$ variable $X$ is said to have a causal influence on a variable $Y$ if a directed path from $X$ to $Y$ exists in every minimal structure consistent with the data. [...] Given $P$, a variable $C$ has a causal influence on variable $E$ if and only if there exists a directed path from $C$ to $E$ in every minimal latent structure consistent with $P$.

7 Do original: We subsume causes and effects under regularities by means of descriptions they satisfy, not by over-all similarity. And we allow a cause to be only one indispensable part not the whole of the total situation that is followed by the effect in accordance with a law. In present-day regularity and a cause is defined (roughly) as any member of any minimal set of actual conditions that are jointy sufficient, given the laws, for the existence of the effect.
Em princípio, parece que uma abordagem minimamente satisfatória, e igualmente problemática ainda assim, sobre o tratamento da causalidade no contexto da linguagem natural, sob o estatuto de uma Semântica Formal, consiste de comprometer-se com as interfaces da Filosofia em relação ao fenômeno, posto o que lhe cabe. Por ora, basta assumir o comprometimento da causalidade com as seguintes subdisciplinas: Filosofia da a) Ciência; b) Linguagem; c) Linguística; d) Mente; e e) Lógica. Esclarecimentos mais substanciais sobre essa estrutura interdisciplinar encontrar-se-ão na seção seguinte. A razão pela qual se defende a centralidade da causalidade em uma abordagem semântica, assim como o núcleo de tal semântica no âmbito de qualquer uma dessas filosofias, está no roteiro de estabelecimento da relação de causa como um fenômeno que tem pertinência linguística, apesar das suas limitações sob tal escopo em uma abordagem exclusivamente disciplinar.

\section{Lógica e linguagem natural: hologramas semânticos}

A seção primeira tratou de esboçar uma verdadeira amálgama de ideias, conceitos e teorização densa, apesar do curto espaço para discuti-la, em torno da noção de causa sob o escopo da linguagem natural, buscando delimitar tal temática a partir da relação entre causalidade e comunicação cotidiana, linguagem científica e núcleos ontológicos de distintas subdisciplinas filosóficas. Na seção atual, ruma-se para uma abordagem metateórica, de caráter metodológico, levando-se em conta os fundamentos da seção anterior, na tentativa de sistematizá-los e elucidá-los.

Costa (2004a; [1988]; 2004b; 2007; 2009; 2016) dedica uma extensa parte de sua bibliografia à defesa de uma opção metodológica de alto custo epistemológico visando a um ainda mais alto benefício teórico. Costa (2004b) acredita que as perguntas de fundamento concernentes 
à Ciência da Linguagem, em torno de sua constituição como tal, não são perguntas que dizem respeito à Linguística, mas à Filosofia da Linguística, e na esteira dessa pressuposição, é necessário admitir tais questões como marginalmente admissíveis para o estatuto da Filosofia da Ciência.

Para o autor, para qualquer que seja a disciplina científica " $\mathrm{x}$ ", é preciso haver uma disciplina " $F$ ", notadamente " $F(x)$ ", que dê conta de seus fundamentos, relegando a " $\mathrm{x}$ " preocupação exclusiva com o conjunto de fenômenos que represente o dado objeto que a disciplina se propõe a investigar. Nesse sentido, parece coerente que a Semântica Formal recorra à metalinguagem lógica para investigar o objeto linguístico do seu recorte, qualquer que seja. Com efeito, Costa (2007) dá seguimento à sua argumentação propondo três secionamentos metateóricos admissíveis para a ciência linguística: a) comunicativo-social, ilustrando-se pelo trabalho de Saussure em seu clássico Cours de Linguistique Générale; b) biológicocognitivo, a exemplo da proposta gerativista de Chomsky; e c) lógico-formal, conforme propõe Montague em suas Gramáticas Categoriais a partir de um sistema formal interpretado.

Para admitir esses três direcionamentos metodológicos, Costa repousa o seu argumento sobre as finalidades a que se presta a linguagem humana, respectivamente: a) comunicar; b) conhecer; e c) pensar. Tal quadro autoriza a interpretação de que os métodos estabelecem uma relação sensível com as manifestações do objeto, decerto sendo oriundo dessa conjetura o posicionamento segundo o qual o método cria o objeto. Essa asserção já havia sido fortemente declarada no trabalho de Saussure (2012 [1916]), sendo retomada por Costa (2007) em sua abordagem de natureza perspectivista, ao exemplo de Giere (2006) e dos fundamentos kantianos.

Costa (2007) segue mais adiante em sua argumentação, estabelecendo que os fundamentos de caráter computacional, natural e interacional, na interação com a Linguística, correspondem respectivamente a interfaces estabelecidas com áreas como a Lógica, a Biologia e a Comunicação ${ }^{8}$. Para o autor, a justificativa metodológica para uma disciplina tal qual a Biolinguística consiste precisamente da relação entre fundamentos de aspecto linguístico e biológico, os quais exijam recursos teóricos de ambas as áreas para explicar a complexidade de certos fenômenos. 0 que se deriva desse processo é, portanto, o caráter explanatório que se reserva ao estabelecimento interdisciplinar, mesma razão pela qual a Semântica Formal, representando a Linguística, se inter-relaciona com os fundamentos de Predicados de Primeira Ordem ou Modalidade Lógica, representantes de uma interface com Lógica Clássica ou Modal, via metalinguagem. De fato, a sua bibliografia é quase integralmente dedicada à descrição da interface entre a lógica e a linguagem natural, estipulando via a sua Metateoria das Interfaces as relações interdisciplinar e intradisciplinar formais para lidar respectivamente com a explanação e a descrição dos fenômenos em voga, conforme se espera esclarecer a partir das Tabelas 1 e 2:

Tabela 1 - Interfaces ou interfaces externas

\begin{tabular}{cc}
\hline Lógica Modal & Linguística Formal \\
Modalidade lógica & Semântica Formal \\
\hline
\end{tabular}

Fonte: Elaborada pelo autor

ou, ainda:

Tabela 2 - Intrafaces ou interfaces internas

\begin{tabular}{lc}
\hline \multicolumn{1}{c}{ Lógica Clássica } & Linguística Formal \\
\hline Cálculo de Predicados de Primeira Ordem & Sintaxe \\
& Semântica \\
& Pragmática \\
\hline Fonte: Elaborada pelo autor. & \\
\hline
\end{tabular}

8 Outras relações são possíveis, dados os fundamentos de cada área de interação. 
Aos fundamentos particulares das áreas interseccionadas, pois, cabe o nível descritivo, o qual é representado por meio das subdisciplinas de tais campos. Uma vez descritas as propriedades em comum entre as subdisciplinas em relação intradisciplinar, o caráter explanatório acerca de tais entidades deve ser estabelecido interdisciplinarmente.

Neste artigo, o que mais se busca enfatizar é o caráter intradisciplinar, lidando com a interação entre as propriedades sintáticas, semânticas e pragmáticas da linguagem natural com a modalidade lógica de uma Lógica Modal de Mundos Possíveis. Os componentes dessa interface triádica se responsabilizam pela constituição do que conhece no modelo de Costa como Linguística Teórica, sendo assumidos como subdisciplinas da Linguística, responsáveis pelas descrições fenomenológicas, assim como seriam a Fonética, a Fonologia, a Morfologia ou a Lexicologia.

A Sintaxe, contudo, é, por meio da sentença, a primeira manifestação macroestrutural de entidades complexas na linguagem natural, dando-se a partir dela o recorte relevante para a discussão. Isso assim se dá porque, segundo as bases semióticas da tradição americana, a relação sintática é a mais básica da tríade, correspondendo à interação entre, no mínimo, dois signos, levando-se em conta a organização desses elementos entre si para estabelecer cadeias cada vez mais complexas de informação linguística. Naturalmente, com a virada chomskyana, anos mais tarde, relegou-se à Sintaxe máxima relevância no bojo da verdadeira revolução copernicana de que consistiu a sua Gramática Gerativo-Transformacional. Para o modelo de Chomsky, a Sintaxe apresenta-se como núcleo da Gramática, motor da maquinaria formal da Faculdade da Linguagem, representada centralmente pela recursão e responsável pela união entre som e sentido.

No seio das Gramáticas Categoriais de Montague (1974), por outro lado, a Sintaxe tem papel subserviente à Semântica, sendo esta o componente gramatical de maior relevância. A Sintaxe serve, antes, ao propósito de bem formar e estruturar adequadamente a proposição, reservando-lhe ainda o custo metodológico da hipótese de regra por regra, segundo a qual para cada regra sintática deve haver a sua contrapartida de natureza semântica, de modo que estrutura e conteúdo estabeleçam uma relação isomórfica entre entidades. O modelo montagueano também admite de maneira bem menos custosa o componente pragmático, assumido na esteira formalista da sua proposta.

A abordagem de Costa (2007), naturalmente, apresenta caráter não apologético, tendo-se em vista que se propõe a uma alternativa metateórica formal de interfaces, relegando as particularidades de cada modelo à compatibilidade específica da relação interteórica, satisfazendo os interesses de pesquisa igualmente específicos que conduzem à necessidade da interface. Nesse sentido, é como se uma Metateoria, qualquer que seja, oferecesse o type, autorizando uma série de tokens compatíveis com a instanciação identitária a partir das características dadas e estabelecidas ad hoc. A relevância de uma proposta metateórica consiste, pois, na possibilidade de que se construam novas teorias, que, sendo híbridas a partir da intersecção formalizada, se apresentem como fruto da relação interdisciplinar e intradisciplinar entre seus fundamentos, constituindo-se assim o design de um objeto inteiramente inédito.

As relações entre Sintaxe, Semântica e Pragmática, pois, têm uma maleabilidade fenomenológica mais ampla do que sugere um modelo teórico ou outro, aspecto garantido pela epistemologia linguística. Dirigidas no interior de um conjunto denominado Linguística Teórica, Costa recorre à noção de significado complexo para tratar de tais subdisciplinas, elencando inclusive outras propriedades linguísticas, de natureza fonológica ou lexical, por exemplo, no ínterim desse quadro. Grosso modo, para o autor, o significado complexo constitui a ampla gama de caraterísticas de uma fenomenologia semiótica, linguística e/ou lógica que apresenta caráter heteromórfico em sua constituição, sendo, em suma, um subconjunto de 
inferências linguísticas que é produzido pelas interfaces entre propriedades envolvidas com o significado.

Na esteira dessa linha argumentativa, buscam-se duas instâncias presentemente: a) caracterizar o fenômeno causal como objeto sui generis de significado complexo, identificando-o no seio das cinco qualidades de filosofia descritas na seção anterior e b) propor o conceito de holografia semântica, por meio do fenômeno causal, como uma extensão de análise e teoria linguística assumida pela Metateoria das Interfaces.

Em relação ao primeiro conjunto de propósitos, pretende-se, agora, sob a luz do perspectivismo científico e da noção metodológica de metateoria, identificar as características que tornam relevante localizar o fenômeno causal no seio de distintas filosofias. Primeiramente, dado que se está lidando, sob o presente escopo, com fundamentos que caracterizam a Linguística enquanto ciência e a linguagem humana enquanto entidade, torna-se coerente elencar as respectivas filosofias que se responsabilizam por tais estatutos como domínios de determinada variável, seja " $\mathrm{F}(\mathrm{x})$ " e " $\mathrm{F}(\mathrm{y})$ ", por exemplo. Se um determinado conjunto de variáveis estiver circunscrito a certo conjunto de domínios, deve-se compreender como produto da intersecção entre tais domínios uma metavariável, que seria o fenômeno de causalidade por excelência.

A razão pela qual a causalidade contribui de maneira tão ostensiva para as disciplinas de Filosofia da Linguagem e da Linguística consiste de a) as muitas maneiras pelas quais se expressa a noção de causa vs. consequência via linguagem natural, nas mais distintas línguas do mundo, e b) as muitas categorias subdisciplinares da Linguística que estão envolvidas na expressão desse fenômeno. Comrie (1981, p. 158, tradução nossa $)^{9}$ declara o seguinte: 9 Do original: Causative constructions have played an important role in the recent history of linguistics,
not only from a typological viewpoint, and also represent an important area of convergence between
Construções causativas têm desempenhado um papel importante na história mais recente da Linguística, não apenas do ponto de vista tipológico, representando também uma importante área de convergência entre Linguística e disciplinas adjuntas tais quais Filosofia (a natureza da causação) e Antropologia Cognitiva (percepção humana e categorização da causação). Internamente à Linguística, construções causativas são importantes porque o seu estudo, ainda que inserido em apenas uma língua, mas talvez mais claramente estabelecido a partir da translinguística, envolve a interação de vários components da majoritária descrição linguística, incluindo semântica, sintaxe e morfologia.

Na esteira dessa declaração, chama-se atenção para o seguinte par de conjunto de domínios continentes de variáveis singulares que são instanciados pela fenomenologia causal, a saber a Filosofia da Mente e da Lógica. Tradicionalmente, ambas as disciplinas estão comprometidas com os fundamentos da Pragmática, caracterizando-se tanto pela interface com os operadores lógicos, destacando-se os trabalhos de Grice (1957; 1967), Bar-Hillel (1954) e Strawson (1952), quanto pela relação com a natureza mentalista, podendo-se citar Searle (1969), Austin (1962) e Wittgenstein (1958).

Contudo, deve-se levar em consideração o fundamento naturalista com o qual a Semântica Formal contemporânea tem-se envolvido, relativizando as suas bases lógicas para interagir com a modularidade cognitiva de uma Faculdade da Linguagem. Esse posicionamento viabiliza a interação da Semântica com o núcleo das Filosofias da Mente e da Lógica, haja vista que uma das discussões de maior fôlego para a Filosofia da Linguística de maneira geral concerne ao estatuto da Semântica, sobre onde estaria afinal o significado, se no mundo ou na mente. Jackendoff, que teve uma contribuição

linguistics and such adjacent disciplines as philosophy (the nature of causation) and cognitive anthropology (human perception and categorization of causation. Internally to linguistics, causative constructions are important because their study, even within a single language, but perhaps more clearly constructions are important because their study, even within a single langualy to linguistics, causative including semantics, syntax and morphology. 
relevante e bivalente para o conceito de Faculdade da Linguagem, endereça um dos problemas mais elementares na esteira dessa discussão concernindo à realidade como elemento central para a determinação do significado, domínio que, de fato, tem relevância para os fundamentos lógico-formais e lógico-modais. Jackendoff caracteriza a versão atualizada do embate em sua análise sobre o problema da determinação da realidade (1992, p. 158, tradução nossa) ${ }^{10}$ :

Versão "filosófica": qual é a relação entre mente e mundo, de tal modo que podemos ter conhecimento sobre a realidade, assim como ter crenças e desejos acerca de coisas no mundo e também nossas sentenças sejam capazes de ser verdadeiras ou falsas? [...] Versão "psicológica": como é que o cérebro funciona como dispositivo físico, de tal modo que o mundo pareça para nós da maneira como o faz e que nos comportemos de maneira efetiva em tal mundo?

A noção de causalidade, pois, apresenta afinidade com os fundamentos ontológicos de disciplinas como Filosofia da Lógica e da Mente, haja vista que desde Hume e Kant tais considerações já apresentavam alta relevância. Nesse sentido, a causalidade parece ser uma entidade fenomenológica passível de ser abordada como ente ontológico por uma teoria semântica moderna, já que tem garantida a sua relevância linguística, por meio das Filosofias da Linguística e da Linguagem, e a sua autenticidade no âmbito formalista e cognitivo.

Por fim, argumentar em favor de que os problemas de Filosofia da Linguística são por acarretamento problemas de Filosofia da Ciência, seria tanto válido e verdadeiro como irrelevante. Uma justificativa adicional,

${ }^{10}$ Do original: "Philosophical" version: What is the relationship of the mind to the world, such that we can have knowledge of reality, such that we can have beliefs and desires about things in the world, and such that our sentences can be true or false? [...] "Psychological" version: How does the brain function as a physical device, such that the world seems to us the way it does, and such that we can behave effectively physical device
in the world? portanto, se faz necessária: a motivação mais genuína para admitir a causalidade como problema de central interesse para a Filosofia da Ciência consiste na sistematização da contribuição de relevância que tem a Semântica para além dos domínios da descrição das línguas naturais. Visto que a causalidade parece figurar como elemento formal primitivo na relação entre proposições do ponto de vista extensional, ainda que a Lógica Clássica não assim a reconheça intensionalmente, assumi-la em seu papel mais basilar de uma proposta científica parece razoável, haja vista que a própria distinção entre causa e explicação é um fator problemático para a relação uso vs. menção, representando propriedades semântico-pragmáticas em sumo.

Estando minimamente descritas as propriedades que entretêm o cerne ontológico da causalidade no seio de um conjunto de pelo menos cinco filosofias, passa-se ao segundo conjunto de objetivos, notadamente acerca do conceito de holografia semântica enquanto extensão de análise e teoria linguística viabilizada pela Metateoria das Interfaces. $\mathrm{O}$ fenômeno causal, naturalmente, figura como eixo condutor dessa proposta, embora tenha caráter meramente ilustrativo para discutir os aspectos metodológicos e epistemológicos da proposta per se. Mais uma vez, a justificativa para essa proposta está repousada na teoria semântica.

Naturalmente, não se está assumindo a causalidade como inserida no âmbito de todas essas disciplinas filosóficas de maneira ad hoc ou aleatória. Espera-se, antes, que a Semântica seja reconhecida como disciplina genuinamente maleável para o tratamento i) metateórico simétrico e ii) holográfico do significado complexo na interface lógica/linguagem natural, inserindo-se como entidade sincrética em cada uma dessas subdisciplinas. Prefere-se chamá-la de sincrética porque é possível que a Semântica instancie diferentes propriedades em cada um desses domínios, e espera-se argumentar em favor de uma universalidade semântica para 
qualquer que seja a disciplina filosófica. Isso vem ao encontro, naturalmente, de propriedades que são tipicamente linguísticas quando reconhecidas no cenário teórico familiar às Ciências da Linguagem, mas que se encontram a serviço de demais instâncias do conhecimento a partir da relação ente (signo) e mundo, como referência, sentido, aboutness, modalidade, conteúdo, conceptualização, "condições-de-verdade" etc.

Nesse sentido, estima-se que a conexão que a causalidade estabelece entre as Filosofias da Ciência, da Linguística, da Linguagem, da Mente e da Lógica seja mediada pela Semântica, como entidade disciplinar que intercede pelas relações interdisciplinares e intradisciplinares. Essa peculiaridade é possível devendo-se a duas instâncias: a) a Semântica é a disciplina linguística que se localiza entre o domínio sintático e o pragmático e b) a Semântica também responde tanto pela linguagem natural quanto pelos sistemas lógicos artificiais, em essência. Isso implica dizer que, ao assumir uma abstração sígnica da Semântica enquanto estatuto, essa disciplina seria, a priori, responsável pela intermediação entre a boa forma estrutural de um dado sistema e a dependência de contexto para a determinação informacional operada pelos usuários abstratos de tal sistema. Curiosamente ou não, uma sentença bem formada pode passar a adquirir status proposicional, se interpretada a partir do conteúdo dos seus elementos intensionais em plena distribuição; um enunciado, paralelamente, também é constituído de conteúdo proposicional, na base das informações contextuais que veicula. $O$ significado complexo de um dado fenômeno, portanto, na interface lógica/ linguagem natural, deve levar em consideração um aspecto mais substancial do que a intraface Sintaxe/Semântica ou Semântica/Pragmática, que seria propriamente o holograma semântico proveniente dessas duas operações.

O termo "holografia semântica", a partir do qual se estrutura esta proposta, é citado por Costa (2004a [1988]), originalmente mencionado de maneira não formalizada, e até mesmo metafórica, em 1988, na sua tese de doutorado sobre a análise metateórica acerca do nome próprio na interface Lógica/Semântica/Pragmática. Uma holografia semântica seria, pois, o processo pelo qual se analisam as projeções do significado em suas mais variadas dimensões, sem recorrer a abstrações mais vagas, dispondo os elementos, antes, em uma distribuição formalizada de interfaces simétricas, ou seja, que contribuam mutuamente na representação ou na composição do ente ontológico inédito. $O$ produto desse processo seria, pois, um holograma semântico, resultado de um procedimento cuja finalidade primordial é refinar a noção de significado complexo, operacionalizando-a.

A principal justificativa para a proposta de hologramas semânticos consiste, sobretudo, na ampla gama de fenômenos que justamente está circunscrita pelo âmbito da significação, multiforme e heteromórfico por natureza. Nesse sentido, parece profícuo propor uma arquitetura formal como a holografia semântica, a qual busque dar conta de abordar uma série de propriedades e elementos que a priori podem parecer ad hoc, mas que, a partir de uma metateoria, se mostram capazes de alinhavar a perspectiva teórico-metodológica adotada e refinar o design ontológico do fenômeno circunscrito.

Nesta proposta, os hologramas semânticos são exponenciados pela interação entre sentença/proposição e proposição/enunciado; isso não significa que outros arranjos não sejam possíveis, sobretudo a partir da interface lógica/linguagem natural, a qual, nesse caso, traz consigo a interação entre significado complexo e racionalidade ampla. Parecem igualmente válidos hologramas semânticos estabelecidos entre modelos pragmáticos near-side vs. far side, por exemplo, ou mesmo entre dados de modais epistêmicos e buléticos. A ideia central é que se assuma a holografia semântica como recurso metateórico para uma investigação em nível interdisciplinar em torno da significação de maneira a satisfazer a devida caracterização do objeto abordado, refletindo assim tanto a real extensão da 
entidade ontológica construída teoricamente, esclarecendo-se suas devidas implicações, potências e natureza, quanto a precisão do recorte em questão.

Dado o específico escopo a partir do qual se desenvolve este trabalho, é imperioso compreender que o estudo na direção da harmonização epistemológica entre Sintaxe/Semântica/Pragmática na esteira da assunção de uma Faculdade da Linguagem em sentido amplo é um impulso norteador para o desenvolvimento de propostas metodológicas e modelos teóricos novos e híbridos no âmbito das linhas de pesquisa em teoria e análise linguística, sendo, sobretudo, a motivação para esta proposta.

\section{0 fenômeno causal na modalidade da interface sintaxe/semântica e semântica/pragmática}

Na expectativa de que as noções de significado complexo, metateoria e holografia semântica estejam minimamente satisfeitas, convém, agora, apresentar alguma ilustração breve sobre as implicações epistemológicas que uma proposta na interface lógica/linguagem natural tem a oferecer para a teoria e a análise linguística.

Para este recorte específico, analisa-se a expressão da causalidade no encalço da modalidade enquanto categoria gramatical de análise semântica, buscando sua complexidade nas interfaces à esquerda da composição holográfica, portanto na Sintaxe, e à direita de tal composto, logo na Pragmática. Em termos mais leigos, trata-se de analisar o conteúdo proposicional em sua forma lógica acerca do dado recorte analisando, também, a relação da distribuição da forma estrutural, de um lado, e do significado dependente de contexto em torno de tal conteúdo informacional, do outro. Grosseiramente, esta proposta leva em conta um debate clássico na literatura, notadamente sobre as propriedades de significado da sentença vs. significado do falante.
Nesta análise em específico selecionam-se dois polos modais, o deôntico e o epistêmico, contrastando-os à luz da noção de conhecimento científico e crença ordinária. Visando a uma análise mais robusta, busca-se a descrição mínima da interface sintaxe/semântica e semântica/pragmática em relação ao modal deôntico e epistêmico. As categorias de modalidade estão assim distribuídas para tratar: i) da boa formação de proposições que expressem questões de fato de ordem causal seguindo um determinado conjunto de regras de acordo com os mundos possíveis acessíveis pela proposição e ii) da dependência de contexto das proposições que expressem crença de ordem causal acordando com um dado conjunto de componentes epistêmicos acessíveis via conteúdo proposicional.

\subsection{Sintaxe e Semântica de modais com noção causal}

Assumindo-se as sentenças abaixo:

(12) Ao nível do mar, a água pode ferver a $100^{\circ} \mathrm{C}$

(13) Ao nível do mar, água deve ferver a $100^{\circ} \mathrm{C}$

(14) Ao nível do mar, a água tem que ferver a $100^{\circ} \mathrm{C}$

parece intuitivo que as três relatem estados do mundo diferentes. A diferença mais substancial concentra-se em (12) em relação a (14), cuja relação distintiva, apesar da forma lógica, possivelmente é amparada no domínio sintático. Cinque $(1999 ; 2006)$ propõe que núcleos sintáticos funcionais são universalmente estruturados de modo a permitir que modais epistêmicos se encontrem em nós mais altos na projeção sintática em todas as línguas até então descritas:

$$
\operatorname{Mod}_{\text {epis }}>\mathrm{T}>\mathrm{Asp}>[\ldots]>\operatorname{Mod}_{\text {deontic necessity }}>\operatorname{Mod}_{\text {deontic possibility }}
$$

de modo que as seguintes paráfrases são possíveis: 
(12a) É possível que a água ferva a $100^{\circ} \mathrm{C}$ -

(12b) Pode ser que a água ferva a $100^{\circ} \mathrm{C}$

(14a) É obrigatório que a água ferva a $100^{\circ} \mathrm{C}$

(14b) Tem que ser que a água ferva a $100^{\circ} \mathrm{C}$

embora algo mais particular ainda seja possível, conforme ilustra (15):

(15) A linguagem humana provavelmente teve que se desenvolver por exaptação

no qual o escopo sobre o qual o modal epistêmico opera está em nível sentencial, ao passo que o escopo deôntico é dirigido para a prejacência argumental da proposição insaturada, conforme se pode analisar em (15a):

(15a) É provável que a linguagem humana tenha tido que se desenvolver por exaptação.

Os exemplos de (16) e (17) podem ser mais claros:

(16) A água deve ferver a $100^{\circ} \mathrm{C}$ em condições ideais

(17) Os dinossauros devem ter se extinguido após a colisão de um meteoro com a Terra

segundo os quais, precisamente (16) estipula um sabor modal deôntico enquanto (17) reserva para si sabor modal epistêmico. Dado o fenômeno composicional, é possível obter-se as seguintes sentenças ainda:

(16a) Provavelmente a água ferve a $100^{\circ} \mathrm{C}$ em condições ideais

(17a) Provavelmente os dinossauros se extinguiram após a colisão de um meteoro com a Terra de modo que a distinção estabelecida entre as duas proposições possa estipular uma relação sintaticamente aceitável para a atribuição de sabor modal epistêmico em ambos os casos, embora não seja possível afirmar que (16a) constitui uma paráfrase, um movimento ou um processo transformacional de (16), ao passo que (17a) admite tal argumento em relação a (17), haja vista que (16) codificaria mais precisamente algo como (18):

(18) Necessariamente a água ferve a $100^{\circ} \mathrm{C}$ em condições ideais.

Apesar de, na forma fonológica, "dever" apresentar-se como entrada lexical detentora de sabor modal em ambos os casos, tanto o domínio semântico quanto o sintático parecem divergir em consonância quanto ao que significa dever ${ }_{K}$ e dever ${ }_{0}$. $O$ trabalho de Kratzer (1977), contudo, argumenta que existe apenas uma entrada lexical, e que o sabor modal será determinado a partir da base modal, viabilizada pelo contexto, determinando, assim, a fonte de ordenação para determinar que mundos são mais ou menos compatíveis com a verdade expressa em leitura deôntica ou epistêmica.

\subsection{Semântica e Pragmática de modais com noção causal}

Kratzer propõe sua abordagem modal admitindo que estruturas dessa categoria são sensíveis ao contexto, de modo que a restrição contextual seja suficiente para determinar o sabor modal de uma proposição. 0 caso em (19):

(19) Jane deve ficar em casa para passar o feriado

pode ser contextualmente atualizado de modo a se confirmar a sua forma lógica pelo contexto, como estrutura atômica dos mundos em que Jane trabalha aos sábados, subdividindo-a em epistêmico e deôntico: 
(19a) Em todos os mundos devidamente ordenados que sejam compatíveis com o conjunto de crenças do falante e mais próximos da sua expectativa, é provável que Jane permaneça em casa para passar o feriado

(19b) Em todos os mundos devidamente ordenados que sejam compatíveis com o conjunto de regras estipulados pelo mundo mais ideal em relação ao atual, é obrigatório que Jane permaneça em casa para passar o feriado.

Enquanto (19a) seleciona um contexto em que idealmente Jane passa o feriado em casa porque habitualmente as suas irmãs visitam a cidade dos pais no fim do ano, sendo Jane a única parente que ainda reside no distrito, (19b) seleciona um contexto no qual Jane passa o feriado em casa porque cumpre pena em prisão domiciliar, não lhe sendo autorizado sair de casa nem mesmo durante as festas de fim de ano.

Stalnaker (1998; 1999) tem sido um dos defensores mais bem-sucedidos da relação entre conteúdo e contexto, sem eliminar as particularidades formais da modalidade lógica ao tratar contextos como microestruturas em relação a mundos possíveis, viabilizando, sobretudo, a dimensão metafísica na esteira de suas considerações. O autor, também, leva em consideração uma série de fatores notadamente pragmáticos, como a intenção do falante, a circunstância da interação comunicativa e o que é passível de ser crença e conhecimento para um falante racional. Assumam-se as sentenças seguintes:

(20) Parece que Jorge não gosta de anchovas, pois deixou todas no prato

(21) Decerto Jorge não gosta de anchovas, pois deixou todas no prato

(22) Jorge não deve gostar de anchovas, pois deixou todas no prato

(23) É provável que Jorge não goste de anchovas, pois deixou todas no prato.
Muito dificilmente, em (22), se encontraria uma interpretação de sabor modal deôntico, e o contexto sequer parece sobrepor-se, haja vista que o conteúdo informacional parece completo o suficiente para saturar a proposição. Em relação aos modais epistêmicos, todos demonstram certo grau de indeterminação ou incerteza por parte do falante, ainda que haja evidência suficiente para asseverar que Jorge não gosta de anchovas. Ainda assim, a relação estabelecida entre Jorge não gostar de anchovas e Jorge não comer uma porção particular de anchovas durante o jantar da noite em que qualquer um dos enunciados tenham tomado lugar não é necessária, sendo apenas uma possibilidade epistêmica elencada pelo agente comunicador. Há, ainda, mais de uma entrada lexical responsável por determinar o sabor modal em questão. Os deônticos, embora também se estruturem entre possíveis e necessários, parecem menos inclinados a possibilidades diversas dentro de um conjunto de mundos factíveis, diferentemente daqueles mundos que são compatíveis ou acessíveis pelo conjunto de crenças do falante.

Contudo, a modalidade deôntica não é menos passível de submeter-se à esfera do que se conhece por significado do falante, conforme ilustram (24) e (25):

(24) É claro que podemos comer carne, nós não cultuamos a Semana Santa

(25) Tem que fazer sol essa semana, ou o casamento será um pesadelo!

enunciados segundo os quais tanto o conteúdo proposicional em (24), que determina grau de obrigação fraco de acordo com o conjunto de regras estipulados pelas crenças do agente, quanto em (25), em que figura o grau de obrigação forte também de acordo com o conjunto de regras estipulado pelo desejo ou expectativa do comunicador, operam por meio de uma modalidade deôntica, ainda sob uma esfera admissível de racionalidade. 
Na subseção anterior, ao tratar-se das particularidades sintáticosemânticas na interação entre modais epistêmicos e deônticos, um aspecto em particular não foi abordado: a noção de racionalidade ampla, que parece ser tanto aplicável à interface sintático-semântica quanto à semânticopragmática, haja vista que o módulo intensional/intencional-conceptual parece admitir tanto conteúdo na interação com a forma quanto conteúdo na interação com o contexto em direção à determinação do significado, que, por mais essa razão, se denomina como significado complexo.

\section{Considerações finais}

Dada uma Faculdade da Linguagem em sentido amplo, as propriedades sintático-semânticas e semântico-pragmáticas podem ser concebidas de maneira não problemática com simetria, assumindo-se uma relação harmônica entre o núcleo recursivo da maquinaria sintática e o componente intensional (intencional)/conceptual, uma vez que, embora a Sintaxe compute as regras e hierarquize as estruturas parametrizadas a partir de princípios exclusivamente formais, no tocante às particularidades do conteúdo, o contexto, como peça-chave para a interação de propriedades externas ao sentido restrito de tal módulo especializado, parece igualmente determinar sobre qual estrutura semântica está sob análise.

Explicitado esse quadro, espera-se, mais uma vez, que tanto as Filosofias da Lógica quanto da Mente estejam a serviço de uma abordagem causal de interfaces na relação entre a lógica e a linguagem natural sob o estatuto da Faculdade da Linguagem. 0 que se espera derivar dessa pesquisa contribui não apenas para a Filosofia da Linguística, dada uma compreensão mais ampla sobre a organização epistemológica das subáreas e da extensão da Linguística por meio de tais subáreas, mas para a Filosofia da Linguagem também, visto que o pesquisador parece estar cada vez mais próximo de distintas respostas para a pergunta sobre o que é a linguagem humana nas mais distintas frentes de investigação em que essa indagação se sobrepõe. Por fim, evidenciando o ente ontológico, as contribuições parecem emergir via significado da sentença vs. significado do falante para uma aproximação mais instigante entre a Filosofia da Ciência e a Semântica do que usualmente já se supõe.

$\mathrm{Na}$ expectativa de que reformulações e adaptações sejam incorporadas ao incipiente modelo que aqui se apresenta, esta proposta busca, em suma, valorizar as bases lógicas, semióticas e linguísticas que permeiam o fazer linguístico na contemporaneidade, enfatizando o caráter pertinente da Filosofia da Linguagem, de um lado, na relação com o objeto, e da Filosofia da Linguística, de outro, no tratamento da disciplina enquanto tal. A causalidade, por sua vez, por mais complexa que se apresente como entidade ontológica, apenas instancia a ampla e profunda complexidade desse objeto ordinário sobre o qual tanto se teoriza, a linguagem.

\section{Referências}

AUSTIN, J. L. How to do things with words? Cambridge: Harvard Univ., 1962.

BACH, E. Natural language metaphysics. Studies in Logic and the Foundations of Mathematics, [S. l.], v. 114, p. 573-595, 1986. https://doi.org/10.1016/S0049-237X(09) 70714-1.

BACH, E. Informal lectures on formal semantics. Albany: State University of New York, 1989.

BAR-HILLEL, Y. Indexical expressions. Mind, Oxford, v. 63, n. 251, p. 359-379, 1954 https://doi.org/10.1093/mind/LXIII.251.359

CARNAP, R. Foundations of Logic and Mathematics. In: NEURATH, O.; CARNAP, R.; MORRIS, C. W. (ed.). International Encyclopedia of Unified Science. Chicago: University of Chicago Press, 1938. p. 139-214. 
CHIERCHIA, G. Plurality of Mass Nouns and the Notion of "Semantic Parameter". In: ROTHSTEIN, S. (ed.). Events and Grammar: Studies in Linguistics and Philosophy, v. 70. Dordrecht: Springer, 1998. p. 53-103. ISBN: 978-1-4020-0289-2. https://doi. org/10.1007/978-94-011-3969-4_4

CHIERCHIA, G.; McCONNEL-GINET, S. Meaning and grammar: an introduction to semantics. 2. ed. Cambridge: MIT Press, 2000

CHOMSKY, N. The minimalist program. Cambridge, Mass.: MIT Press, 1995.

CINQUE, G. Adverbs and Functional Heads: a crosslinguistic perspective. New York: Oxford University Press, 1999.

CINQUE, G. Restructuring and functional heads: the cartography of syntactic structures. New York: Oxford University Press, 2006.

COMRIE, B. Language universals and linguistic typology. Basil Blackwell: Oxford, 1981.

COSTA, J. C. Os Enigmas do Nome - Na interface Lógica/Semântica/Pragmática. Porto Alegre: EDIPUCRS, 2004a [1988].

COSTA, J.C. Metateoria linguística (considerações ao nível de filosofia da ciência). Revista da ADPUCRS, Porto Alegre, n. 5, p. 25-32, 2004b.

COSTA, J. C. The sciences of language: communication, cognition and computation. In: AUDY, J; MOROSINI, M. Innovation and interdisciplinarity in the university. Porto Alegre: EDIPUCRS, 2007. p. 345-376.

COSTA, J. C. Lógica e linguagem natural nas interfaces. In: PEREIRA, A. F.; COSTA, J. C. (ed.). Linguagem e cognição: relações interdisciplinares. Porto Alegre: EDIPUCRS, 2009. p. 132-142.

COSTA, J. C. Na interface entre lógica formal e lógica prática: inferências múltiplas. Letras de Hoje, Porto Alegre, v. 51, n. 3, p. 411-418, 2016. Disponível em: http://dx.doi. org/10,15448/1984-7726.2016.3.25482. Acesso em: 1 jan. 2018.
De PIERRIS, G.; FRIEDMAN, M. Kant and Hume on Causality. In: ZALTA, E. N. (ed.). The Stanford Encyclopedia of Philosophy (Winter 2018 Edition). Disponível em: https:// plato.stanford.edu/archives/win2018/entries/kant-hume-causality/. Acesso em: 1 mar. 2019.

GIERE, R. Scientific perspectivism. Chicago: University of Chicago Press, 2006. https:// doi.org/10.7208/chicago/9780226292144.001.0001

GRICE, H.P. Meaning. Philosophical review, Ithaca, v. 66, p. 377-88, 1957. https://doi. org $/ 10.2307 / 2182440$

GRICE, H. P. Logic and conversation. Cambridge: Harvard University, 1967. (William James lectures)

HEIM, I.; KRATZER, A. Semantics in generative grammar. New Jersey: Wiley-Blackwell, 1998.

HORNSTEIN, N. Logic as grammar. Cambridge: The MIT Press, 1984.

JACKENDOFF, R.S. Language of the mind: essays on mental representation. Cambridge: MIT Press, 1992. https://doi.org/10.7551/mitpress/4129.001.0001

KRATZER, A. The notional category of modality. Worlds, Words, and Contexts. (Eds.) Eikmeyer, H.-J. and H Rieser. Berlín: de Gruyter, 1981. p. 38-74.

KRATZER, A. Modality. von STECHOW, A; D. WUNDERLICH, D. (eds.). Semantics: An International Handbook of Contemporary Research. [Oxford]: [Oxford University Press], 1991. p. 639-650.

KRATZER, A. Constraining premise sets for counterfactuals. Journal of Semantics, [S. l.], v. 22, n. 2, p. 153-158, 2005. Acesso em: 1 jan. 2018. https://doi.org/10.1093/jos/ ffh 020

KRATZER, A. Modality for the 21st Century. Proceedings... In: INTERNATIONAL CONGRESS OF LINGUISTS, 19., Geneva, 2013. p. 181-201 
KRATZER, A. Evidential Moods and the Semantics of Attitude and Speech Reports. Talk given at the University of Pennsylvania (May 5, 2016). In: SYNCART WORKSHOP, 1. Siena, July 13, 2016, and the University of Connecticut (September 9, 2016), 2016.

KRIPKE, S. Naming and necessity. Oxford: Basil Blackwell, 1980.

LEWIS, D. Causation. The Journal of Philosophy, New York, v. 70, n. 17, p. 556-567, 1973. https://doi.org/10.2307/2025310

LUDLOW, P. Semantics, tense, and time: an essay in the metaphysics of natural language. Cambridge: MIT Press, 1999. https://doi.org/10.7551/mitpress/6170.001.0001

MONTAGUE, R. Formal philosophy: selected papers. In: THOMASON, R. H. (ed.). New Haven: Yale University Press, 1974.

MORRIS, C. Foundations of the theory of signs. In: NEURATH, O.; CARNAP, R.; MORRIS C. (ed.). International encyclopaedia of Unified Science, v. 1, n. 2. Chicago: University of Chicago Press, 1938. p. 77-136.

MORRIS, W. E.; BROWN, C. R., David Hume. In: ZALTA, E.N. (ed.). The Stanford Encyclopedia of Philosophy (Spring 2017 Edition). Disponível em: https://plato. stanford.edu/archives/spr2017/entries/hume/. Acesso em: 29 jun. 2018.

PEARL, J. Causality: models, reasoning, and inference. Cambridge: Cambridge University Press, 2000.

PEIRCE, C. S. Collected papers. Harvard University Press: Cambridge, USA, 1931-1958.

SAUSSURE, F. Curso de linguística geral. 28. ed. São Paulo: Editora Cultrix, 2012 [1916]

SEARLE, J. R. Speech acts: an essay in the philosophy of language. London: Cambridge Univ., 1969. https://doi.org/10.1017/CB09781139173438

STALNAKER, R. On the representation of context. Journal of logic, language and information, Dordrecht, v. 7, n. 1, p. 3-19, 1998. https://doi. org/10.1023/A:1008254815298
STALNAKER, R. Context and content. Oxford: Oxford University press, 1999. https://doi. org/10.1093/0198237073.001.0001

STRAWSON, P. F. Introduction to Logical Theory. London: Methuen, 1952.

WITTGENSTEIN, L. Philosophical Investigations. Oxford: Blackwell, 1958. 